\title{
SESSENTA ANOS DA COMISSÃO INTERAMERICANA DE DIREITOS HUMANOS: IMPLICAÇÕES NO ESTADO DEMOCRÁTICO DE DIREITO BRASILEIRO
}

\author{
SIXTY YEARS OF THE INTER-AMERICAN COMMISSION ON HUMAN RIGHTS: \\ IMPLICATIONS IN THE DEMOCRATIC STATE OF BRAZILIAN LAW
}

\author{
Beatriz Canhoto Lima* \\ Enrique Ricardo Lewandowski*
}

\begin{abstract}
Resumo:
Com os acontecimentos históricos pautados pelo aviltamento dos direitos humanos, o Sistema Interamericano de Direitos Humanos assume um importante papel na promoção da defesa desses direitos, irradiando efeitos no âmbito doméstico dos respectivos Estados-membros, incluindo o Brasil. Nesta perspectiva, a presente investigação assumiu o problema expresso no seguinte questionamento: quais impactos da Comissão Interamericana de Direitos Humanos no processo de consolidação do Estado Democrático de Direito brasileiro? A pesquisa, de natureza qualitativa e de cunho descritivo-analítico, adotou como procedimentos metodológicos: a revisão bibliográfica, análise documental, análise legislativa no âmbito interno e levantamento de políticas públicas, no contexto brasileiro, realizadas com o escopo de atender às demandas elencadas pela Comissão. Os resultados da análise dos casos envolvendo o Brasil revelam uma notória deficiência do Estado brasileiro referente ao cumprimento de medidas que envolvam diferentes agentes estatais e órgãos governamentais relacionados, todavia, por mais que se observe a dificuldade brasileira no tocante ao grau de cumprimento das medidas oriundas do Sistema Interamericano, nota-se que as decisões da Comissão influenciaram na adoção de políticas públicas e legislativas, contribuindo para o processo de consolidação de um Estado de Direito Democrático.

Palavras-chave: Direitos Humanos. Comissão Interamericana. Estado Democrático de Direito. Fundamentos do Estado brasileiro.
\end{abstract}

\begin{abstract}
:
With the historical events marked by the degradation of human rights, the InterAmerican System of Human Rights assumes an important role in promoting the defense of human rights, irradiating effects in the domestic sphere of the respective member states, including Brazil. From this perspective, the present investigation has taken on the problem expressed in the following question: what are the impacts of the Inter-American Commission on Human Rights in the process of consolidating
\end{abstract}

\footnotetext{
Discente da Faculdade de Direito da Universidade de São Paulo - USP, cursando disciplinas de Dupla Graduação a partir de convênio firmado entre a Faculdade de Direito da USP e a Universidade Jean Moulin - Lyon 3 (Convênio PITES). Bolsista de iniciação científica pela Fundação de Amparo à Pesquisa do Estado de São Paulo (FAPESP) entre os anos de 2016 e 2017.

** Professor Titular e Livre-Docente da Faculdade de Direito da Universidade de São Paulo - USP e Ministro do Supremo Tribunal Federal - STF.
} 
the democratic state under Brazilian Law? This research, from a qualitative and descriptive-analytical nature, adopted as methodological procedures: a bibliographical review and documental analysis, domestic legislation inquiry and a survey of public policies in the Brazilian context, carried out with the scope of meeting the demands listed by the Commission. The results of the analysis of the cases involving Brazil reveal a notorious deficiency of the Brazilian State regarding the fulfillment of measures involving different state agents and related government agencies. However, despite the Brazilian difficulty regarding the degree of fulfillment of measures originating from the Inter-American System, the decisions of the Commission have influenced the adoption of public and legislative policies, contributing to the process of consolidation of a Democratic Rule of Law.

Keywords: Human rights. Inter-American Commission. Democratic State. Fundamentals of the Brazilian State.

\section{Introdução}

No decurso da história, vislumbra-se que o papel do Estado na ordem socioeconômica denota pontos de progressão e regressão, notadamente em âmbito relativo à promoção, com consequente concretização, dos direitos humanos. Segundo Bobbio (2004, p. 4), o plano inicial de avanço na afirmação dos direitos do homem decorre de uma "radical inversão de perspectiva, característica da formação do Estado moderno, na representação da relação política, ou seja, na relação Estado/cidadão", encarada pelo ponto de vista dos direitos dos cidadãos e não do soberano, visto que, para se compreender a sociedade, "é preciso partir de baixo, ou seja, dos indivíduos que a compõem”. Como nos ensina Ranieri (2013, p. 195), o Estado de Direito é designado como um tipo de Estado, no qual o sistema jurídico atua em favor da tutela dos direitos humanos e da limitação do poder estatal, ou mesmo como modelo prescritivo de organização sociopolítica, cujo poder e cujas atividades estão regulamentados pela lei, ou princípio constitucional, consagrando-se o princípio da legalidade e a garantia da liberdade.

Tal entendimento contempla a evolução histórica do conceito de Estado de Direito, advindo das conquistas do movimento liberal-burguês, que proclamava a contenção da tirania do poder estatal frente aos direitos e garantias individuais; passando pela superação do Estado Liberal de Direito, imparcial e ausente, em prol do Estado Social de Direito, cuja intervenção estatal fora tomada como atitude central para a implementação de direitos sociais, o reconhecimento e a materialização do princípio de solidariedade e de justiça social. Todavia, com a mudança no cenário social, a concepção de Estado de Direito reformula-se, novamente, e ocorre uma orientação material do Estado Social à democracia. O Estado de Direito deve, nesse aspecto, criar condições que favoreçam efetivamente o desenvolvimento de seus cidadãos; tal reformulação originase da teorização do Estado Democrático de Direito, fundamentado em duas concepções 
centrais, a saber, o Estado limitado pelo direito e o poder político estatal legitimado pelo povo (CANOTILHO, 2004, p. 231).

Nesse sentido, esse modelo apresenta organização embasada na legitimidade de uma Constituição, que advém da vontade popular, combinada ao princípio democrático, e constitui uma democracia representativa, participativa e pluralista. Em consonância ao que afirma Afonso da Silva (1992, p. 122), a essas características, soma-se a vigência de um sistema de direitos fundamentais, com o escopo de serem superadas as desigualdades sociais e regionais, para que se instaure um regime democrático, assente nos princípios da igualdade, divisão de poderes, legalidade e segurança jurídica, que efetive a justiça social.

De sorte, o Estado Democrático de Direito é estabelecido no Brasil com o advento de nova ordem constitucional, edificada a partir da Constituição de 1988. O presente instrumento, logo em seu art. $1^{\circ}$, consagra seus elementos fundantes, quais sejam, a soberania, a cidadania, a dignidade da pessoa humana, os valores sociais do trabalho e da livre iniciativa, o pluralismo político; e, ainda, determina o princípio democrático, ao estabelecer que "todo poder emana do povo, que o exerce por meio de representantes eleitos ou diretamente, nos termos desta Constituição". Nesse sentido, como elementos constitutivos do Estado brasileiro, os direitos humanos atuam como mecanismo basilar para a consecução do princípio democrático, consagrado no modelo de Estado vigente.

Ora, para que o Estado brasileiro supere as desigualdades sociais e regionais e instaure um sistema que realize justiça social, faz-se mister uma postura, preliminarmente, de promoção dos direitos inerentes a qualquer ser humano em âmbito nacional - direitos fundamentais - e internacional - direitos humanos. E, dentre os mecanismos criados para a promoção e defesa dos direitos humanos, o presente estudo buscou conhecer o Sistema Interamericano de Direitos Humanos, em especial, a Comissão Interamericana de Direitos Humanos (CIDH), que nos revela situações fáticas de desrespeito aos direitos humanos traduzidas nos casos brasileiros, espraiando-se reflexos no cenário interno do país rumo ao processo de consolidação do Estado Democrático de Direito no Brasil.

Nessa perspectiva, impende ao Sistema Interamericano de Direitos Humanos (SIDH), dotado de um dispositivo legal responsável pela ratificação em âmbito normativo da efetividade do sistema, qual seja, a Convenção Interamericana de Direitos Humanos, celebrada em São José da Costa Rica, no ano de 1969, promover a internacionalização dos direitos do homem nas Américas, consolidando-se como alicerce protetivo aos direitos fundamentais.

De sorte, o Estado brasileiro aderiu à missão precípua de promoção e defesa dos direitos inerentes ao homem, tornando-se país signatário do Pacto de São José da Costa Rica e incorporando a Convenção Americana ao ordenamento jurídico interno, por força do art. $5, \S 2^{\circ}$. Indo adiante, o SIDH não somente irradia efeitos na democracia brasileira, como contribui na hermenêutica dos tribunais brasileiros, principalmente no que se refere 
ao Supremo Tribunal Federal, posto que não seria satisfatório incorporar tratados de direitos humanos na ordem jurídica interna, mas sim aderir à interpretação internacional desses dispositivos. Desse modo, cabe ao STF harmonizar seu posicionamento referente aos direitos e garantias fundamentais com a posição hermenêutica internacional. Ademais, o legislador constituinte, ao reconhecer a dignidade da pessoa humana como fundamento do Estado brasileiro, assinala para o processo de valorização que o sistema constitucional atribui aos direitos humanos, em consonância com o período histórico destacado anteriormente; destarte, o Estado existe em função do homem, este nunca poderá ser simples meio para a atuação daquele (GUERRA, 2008).

Diante disso, o presente estudo assumiu como objetivo central investigar impactos do SIDH, notadamente da $\mathrm{CIDH}$, a partir de uma abordagem qualitativa de suas recomendações, para a consolidação dos direitos humanos no Brasil. A presente investigação revela impactos políticos e jurídicos dos posicionamentos da Comissão, no que tange ao Estado brasileiro, na promoção de políticas públicas internas e na produção de decisões legislativas em âmbito interno, que contribuem para a democracia no Brasil.

\section{Metodologia}

A investigação foi desenvolvida a partir de uma abordagem qualitativa, com o intuito de analisar as recomendações e as decisões da Comissão Interamericana de Direitos Humanos, dialogando com o referencial teórico estudado preliminarmente. Para isso, a investigação apoiou-se em uma pesquisa documental, caracterizada pela análise de informações em fontes primárias, como relatórios, processos judiciais, legislação, entre outros, que se constituem em dados originais, a partir dos quais se obtém uma correlação entre os fatos a serem analisados (OLIVEIRA, 2007). Partindo-se dessa pesquisa documental, tornou-se possível a observação de impactos das recomendações e decisões da CIDH no Estado Democrático de Direito brasileiro.

A pesquisa, de cunho descritivo-analítico, objetivou identificar, descrever e analisar tais implicações por intermédio de um levantamento das principais violações do Estado brasileiro referentes à inobservância dos direitos humanos. Para a coleta e análise de dados, foram utilizados os seguintes procedimentos metodológicos: - levantamento e análise bibliográfica com a finalidade de ampliação de conhecimentos a respeito dos direitos humanos, do Sistema Interamericano, com destaque à Comissão Interamericana, visando ao estabelecimento de uma base teórica consistente para a coleta e análise dos documentos; - e a análise documental que, por sua vez, dispôs de um levantamento de jurisprudência em âmbito interno e externo concernente aos direitos humanos, da qual o Estado brasileiro figure como parte, com análise de conteúdo posteriormente. 


\section{Comissão Interamericana de Direitos Humanos contextualizada}

$\mathrm{O}$ século XX foi um período marcado pela eclosão de grandes conflitos mundiais, em que algozes governantes estiveram à frente de processos de aviltamento a direitos humanos, como se nota com a mortuária desencadeada nas Grandes Guerras Mundiais e em Regimes Totalitários, como o nazifascismo. Uma era de manifesta lógica de destruição em que se constatou a negação do valor da pessoa humana, com cometimentos de genocídios e afrontas à dignidade humana.

Em resposta às atrocidades cometidas, a Comissão Interamericana de Direitos Humanos (CIDH), que completou sessenta anos, em 2019, desde sua criação em 1959, foi instituída no Chile, mediante Quinta Reunião de Ministros de Relações Exteriores, dando início a suas funções no ano subsequente, com a aprovação de seu Estatuto e eleição de seus membros pelo Conselho da OEA. Determinou-se sua criação com características similares à Comissão de Direitos Humanos, presente no seio das Nações Unidas, justificando tais medidas por se acreditar "ser essencial que esses direitos sejam protegidos por um sistema jurídico, para que os homens não sejam atirados ao expediente extremo da revolta contra a tirania e a opressão" (HANDBOOK OF EXISTING RULES PERTAINING TO HUMAN RIGHTS, apud LEWANDOWSKI, 1984, p. 103).

A princípio, suas atribuições continham restrições, limitando-se a promover os direitos enunciados na Declaração Americana no continente, a apenas agir em situações alarmantes que envolvessem a manutenção da paz no continente e, por fim, a servir como órgão consultivo (TRINDADE, 1999, apud PIOVESAN, 2000, p. 111). Posteriormente, no ano de 1967, com a reforma da Carta da OEA pelo Protocolo de Buenos Aires, as atribuições da Comissão deixaram de ser apenas preventivas para a transformarem em autêntico órgão internacional de cumprimento dos compromissos assumidos pelos Estados membros da OEA, notadamente no tocante à promoção e ao resguardo dos direitos humanos. Segundo Alves (1994, p. 78) "as atribuições e status institucional foram, porém, sucessivamente fortalecidos" com a entrada em vigor da Convenção Americana de Direitos Humanos, em 1979, e, consequentemente, a Comissão passa a realizar um duplo tratamento normativo, concernente à Carta da OEA e à Convenção, além do estabelecimento de "um procedimento bifásico de promoção dos direitos protegidos: há uma etapa, indispensável, perante a Comissão Interamericana de Direitos Humanos (Comissão IDH) e uma eventual segunda etapa perante a Corte Interamericana" (RAMOS, 2014, p. 320). Atualmente, consiste em órgão de monitoramento da Convenção e, conjuntamente, integrante da Organização dos Estados Americanos (OEA). Com sede situada em Washington, nos Estados Unidos, a Comissão, regulamentada no capítulo VII pela Convenção Americana de Direito Humanos (1969), compõe-se de sete membros, “eleitos a título pessoal pela Assembleia Geral da Organização, que deverão ser pessoas de 
alta autoridade moral e de reconhecido saber em matéria de direitos humanos", permanecendo por quatro anos, com possibilidade de uma única reeleição, de acordo com art. $2^{\circ}$ do seu regulamento.

Dentre as funções primordiais da Comissão está a promoção, observância e defesa dos direitos humanos no continente e, para alcançar esse desiderato, cabe ao respectivo órgão, de acordo com o art. 41 da Convenção Americana de Direitos Humanos (1969): estimular a consciência dos direitos humanos nos povos da América; formular recomendações aos governos dos Estados membros no sentido de que adotem medidas progressivas em prol dos direitos humanos no âmbito de suas leis internas e seus preceitos constitucionais; preparar estudos ou relatórios que considerar convenientes para o desempenho de suas funções; solicitar aos governos dos Estados membros informes sobre as medidas que adotarem em matéria de direitos humanos; atender às consultas formuladas pelos Estados membros sobre questões relacionadas aos direitos humanos, prestando-lhes, na medida de suas possibilidades, o assessoramento que eles lhe solicitarem; atuar com respeito às petições e outras comunicações, no exercício de sua autoridade, conforme os disposto nos arts. 44 a 51 da presente Convenção; e apresentar um relatório anual à Assembleia Geral da Organização dos Estados Americanos. Além das atribuições descritas no art. 41 supra, sua principal função é a de receber petições individuais, procedimento considerado de adesão obrigatória, e interestatais, de adesão facultativa, contendo alegações de violações de direitos humanos (RAMOS, 2014, p. 320).

4. Análise sobre impactos de casos brasileiros: políticas públicas e medidas legislativas

O presente tópico permite que se avalie a forma como o Brasil se relaciona com a Comissão e o modo como suas decisões podem contribuir para reforçar o sistema protetivo de direitos humanos no país, a partir do fornecimento de subsídios para a concretização dos elementos fundantes do Estado Democrático de Direito, notadamente a democracia e a dignidade da pessoa humana. Conforme exame dos casos envolvendo o Estado brasileiro no órgão do Sistema Interamericano, foram selecionados, para objeto do presente estudo, as recomendações advindas dos relatórios de mérito e as soluções amistosas realizadas na Comissão, englobados pelo período de 1973 a 2019. Por meio do exame dos dados coletados nos documentos supramencionados, analisaram-se efeitos práticos das resoluções e recomendações feitas pela Comissão, no tocante à adoção de políticas públicas e medidas legislativas. Não se pretende, com isso, esgotar a análise das influências da Comissão Interamericana exercida no Estado brasileiro, mas se objetiva destacar como tal órgão contribuiu para o processo de consolidação da democracia e 
da proteção dos direitos humanos no Brasil através da tomada de políticas públicas e legislativas nesse sentido.

Inicialmente, foram identificados os casos envolvendo o Brasil segundo os relatórios de mérito realizados pelo respectivo órgão, assim como relatórios concernentes à solução amistosa entre as partes envolvidas. Os primeiros contêm conclusões sobre se os fatos do caso ora analisado configuram violações aos direitos humanos. Caso se conclua por sua ocorrência, o relatório de mérito engloba recomendações feitas ao Estado que podem estar destinadas a: eliminar os atos violadores de direitos humanos; esclarecê-los e conduzir investigação e sanção adequadas, reparar os danos ocasionados, introduzir mudanças no ordenamento jurídico interno, e/ou requerer a adoção de outras medidas ou ações estatais com o propósito de evitar a ocorrência de violações similares posteriormente. Dispende destacar que os relatórios de mérito que a Comissão aprova anualmente distinguem-se, em número, dos que foram publicados; isso ocorre devido ao fato de que quando se aprova relatório de mérito, conforme o art. 50, da Convenção Americana, o mesmo possui caráter confidencial, devendo a Comissão notificar unicamente as partes (o Estado e o peticionário). Os informes aprovados podem ser publicados posteriormente, se a Comissão assim o decide, de acordo com o art. 51.3 do documento supramencionado. Na hipótese de envio do caso à Corte Interamericana, o informe do respectivo caso é publicado na página de casos submetidos à jurisdição da Corte. No tocante às soluções amistosas, tem-se um processo que depende da vontade das partes e consiste em negociações endereçadas à resolução da questão sem necessidade de completar o processo do contraditório, ocorrendo sob a supervisão da Comissão. Nesse sentido, quando o Estado e a parte peticionária resolvem o assunto por intermédio de uma solução amistosa e firmam acordos, a CIDH realiza o prosseguimento dos pontos acordados. Ao se atingir o cumprimento de todos ou da maior parte dos pontos essenciais acordados entre as partes, a CIDH aprova e publica um Informe de Solução Amistosa referente ao caso, após o qual culmina sua tramitação (CIDH, 2020). Para a referida análise, estipularam-se os casos, a partir dos relatórios de mérito englobados pelo período de 1973 a 2019, contemplando um total de vinte relatórios de mérito e dois de solução amistosa. Os dados presentes nos informes confidenciais da Comissão, que não foram publicados em sua página na internet, não fizeram parte dessa pesquisa. Cabe ressaltar que, devido aos limites do artigo, não foi possível apresentar todos os casos, portanto, optou-se em expor casos representativos.

Como primeira abordagem, tem-se o caso Carandiru, em que o Estado brasileiro fora denunciado, em síntese, pela morte de 111 presos (dos quais, 84 estavam sendo processados, mas ainda não tinham sido condenados) e a lesões graves sofridas por outros internos durante o massacre perpetrado por policiais ao invadirem a Casa de Detenção Carandiru, situada em São Paulo, para debelar uma rebelião (CIDH, 1999). 
Como informado à Comissão, no relatório de mérito n. 34/2000, após as ocorrências, foram tomadas medidas $^{1}$ relativas à criação da Secretaria de Administração Penitenciária do Estado de São Paulo, ${ }^{2}$ à inclusão obrigatória de um curso de direitos humanos na formação dos policiais desse estado e à desativação do Complexo Penitenciário do Carandiru, como passo inicial ao cumprimento de um dos propósitos do Programa Nacional de Direitos Humanos, o qual prevê a desativação de estabelecimentos carcerários em desacordo com os patamares mínimos penitenciários internacionais. Atualmente, o presídio encontra-se totalmente desativado, com exceção à ala hospitalar, com diversos prédios demolidos e outros mantidos para serem reaproveitados; o Governo do Estado de São Paulo construiu o Parque da Juventude, ${ }^{3}$ além de instituições educacionais e de cultura, como a Escola Técnica Estadual.

Em seguida, dá-se prosseguimento à análise com outro caso de grande destaque, qual seja, Caso n. 12.051, Maria da Penha Maia Fernandes, referente à denúncia acerca da tolerância por parte do Estado brasileiro em não tomar, por mais de quinze anos, medidas efetivas e necessárias para punir a violência perpetrada por Marco Antônio Heredia Viveiros em prejuízo de sua então esposa Maria da Penha Maia Fernandes, no decorrer de sua convivência matrimonial, que culminou em uma tentativa de homicídio e em agressões posteriores. Como produto dessas agressões, Maria da Penha padece de paraplegia irreversível e outras doenças desde o ano de 1983 (CIDH, 2000). Em esforço para cumprir com as recomendações contidas no relatório de mérito n. 54/2001, realizado pela Comissão, foi promulgada, em 7 de agosto de 2006, a Lei n. 11.340/2006 (Lei Maria da Penha), que cria mecanismos para coibir a violência doméstica e familiar contra a mulher, nos termos do $\S 8^{\circ}$ do art. 226 da Constituição Federal, da Convenção sobre a Eliminação de Todas as Formas de Discriminação contra as Mulheres e da Convenção

\footnotetext{
1 A Comissão informou seu reconhecimento de que o Estado brasileiro realizou medidas para melhorar as condições carcerárias, com destaque à construção de novas instalações penitenciárias, à fixação de novas normas de detenção e ao estabelecimento, no estado de São Paulo, de uma secretaria especial encarregada desses assuntos. Disponível em: http:/www.cidh.oas.org/annualrep/99port/Brasil11291.htm. Acesso em: 21 mar. 2020.

2 Como decorrência dessa preocupação, a Lei n. 8.209, de 04/01/93 criou o Decreto n. 36.463, de 26/01/1993, organizou a Secretaria da Administração Penitenciária, a primeira no Brasil a tratar com exclusividade do referido segmento. A Secretaria da Administração Penitenciária se destina a promover a execução administrativa das penas privativas de liberdade, das medidas de segurança detentivas e das penas alternativas à prisão, cominadas pela justiça comum, e proporcionar as condições necessárias de assistência e promoção ao preso, para sua reinserção social, preservando sua dignidade como cidadão. Disponível em: http://www.sap.sp.gov.br/. Acesso em: 21 mar. 2020.

3 O Parque da Juventude propiciou alterações na paisagem da Zona Norte de São Paulo desde 2003, ao substituir o Complexo Penitenciário Carandiru por uma área de lazer e entretenimento ao ar livre. O espaço também abarca a Biblioteca de São Paulo, com mais de 35 mil títulos, e o Acessa São Paulo, programa de inclusão digital do Governo do Estado. No local, foram mantidos referenciais históricos da época do Carandiru. Disponível em: http://acessajuventude.webnode.com.br/historia-do-carandiru/. Acesso em: 21 mar. 2020
} 
Interamericana para Prevenir, Punir e Erradicar a Violência contra a Mulher; dispõe sobre a criação dos Juizados de Violência Doméstica e Familiar contra a Mulher; altera o Código de Processo Penal, o Código Penal e a Lei de Execução Penal; e dá outras providências (BRASIL, 2020). Em seguida, como informado no Relatório de Mérito do presente caso, o Estado adotou uma série de medidas para dar eficácia à Lei Maria da Penha, dentre elas, destaca-se o acordo de colaboração firmado entre a Secretaria de Políticas para Mulheres (SPM) e o Conselho Nacional de Justiça (CNJ), diante do qual a SPM integrará o programa Justiça Plena, responsável por monitorar e dar transparência ao andamento de processos de grande repercussão social, a partir de cinco processos relacionados com a Lei Maria da Penha, sendo monitorados pelo respectivo programa. Dentre os mecanismos estatais criados para se garantir a defesa dos direitos das mulheres, tem-se o Fórum Nacional de Juízes de Violência Doméstica e Familiar contra a Mulher (Fonavid), criado em 2009, em parceria entre o Ministério da Justiça, Secretaria de Políticas para Mulheres e Conselho Nacional de Justiça, cujo objetivo é manter um espaço permanente de discussões sobre o tema onde os participantes compartilham experiências, definem a uniformização dos procedimentos, decisões dos juizados e varas especializadas em violência doméstica e familiar contra a mulher sob a perspectiva da efetividade jurídica e o aperfeiçoamento dos magistrados e equipes multidisciplinares. Também, tem-se a criação da Comissão da Mulher no Conselho Nacional dos Defensores Públicos Gerais (CONDEGE), com objetivo de congregar defensores públicos em atuação na área em questão, para a troca de experiências, o aprimoramento profissional, o fortalecimento da atuação institucional buscando a formalização de projetos e a elaboração de propostas de atuação. Buscando trazer efetividade à Lei Maria da Penha, citam-se dois julgamentos perante o Supremo Tribunal Federal, ocorridos em 9 de fevereiro de 2012, que resolveram dúvidas relativas à constitucionalidade de suas disposições, a seguir expostos.

Ação Direta de Inconstitucionalidade n. 4.424/DF, sob relatoria do Ministro Marco Aurélio, em que se julga procedente a ação direta para, dando interpretação conforme aos arts. 12, inciso I, e 16, ambos da Lei n. 11.340/2006, assentar a natureza incondicionada da ação penal em caso de crime de lesão corporal, pouco importando a extensão desta, praticado contra a mulher no ambiente doméstico, nos termos do voto do relator e por maioria, em sessão presidida pelo Ministro Cezar Peluso (BRASIL, 2012c). Nesse sentido caminha o voto do Ministro Ricardo Lewandowski, com destaque ao seguinte trecho:

Gostaria de salientar que penso que nós estamos diante de um fenômeno psicológico e jurídico que os juristas denominam de vício da vontade, que é conhecido e estudado desde os antigos romanos. E as mulheres - como está demonstrado estatisticamente, isso foi salientado por todos os oradores e todos os magistrados que me antecederam - 
não representam criminalmente contra o companheiro ou o marido em razão da permanente coação moral e física que sofrem, e que inibe a sua livre manifestação da vontade (BRASIL, 2012c, p. 67).

Em complemento, tem-se a Ação Declaratória de Constitucionalidade n. 19/DF, sob a mesma relatoria, em que se julga procedente a ação para declarar a constitucionalidade dos arts. $1^{\circ}, 33$ e 41 da Lei n. 11.340/2006 - Lei Maria da Penha - nos termos do voto do relator e por unanimidade, em sessão presidida pelo Ministro Cezar Peluso. Novamente, dispõe-se de trecho do voto do Ministro Ricardo Lewandowski para elucidar a questão:

esta Lei Maria da Penha, tal como o Estatuto da Criança e do Adolescente e também o Estatuto do Idoso, mais do que simples diplomas normativos de caráter ordinário, que fixam regras de conduta, na verdade, representam verdadeiras ações afirmativas que visam a eliminar ou atenuar gravíssimas distorções históricas (...) Esta lei, como já foi dito aqui, longe de ser anti-isonômica, procura superar aquela visão que se tinha no Estado Liberal, a partir dos Séculos XVIII e XIX, e talvez até no começo do Século $\mathrm{XX}$, de uma igualdade meramente formal, dando concreção, como já foi dito aqui, a uma igualdade material. Aliás, uma visão que vem desde Aristóteles, como já disse aqui o Ministro Marco Aurélio, trazendo à colação o grande Rui Barbosa, é tratar desigualmente os desiguais na medida de sua desigualdade (BRASIL, 2012b, p. 50, ).

Dando continuidade às medidas realizadas pelo Estado brasileiro, como resultado da cooperação entre o Poder Judiciário, o Ministério Público, a Defensoria Pública e o Governo Federal, por meio da Secretaria de Políticas para as Mulheres da Presidência da República e o Ministério da Justiça, instituiu-se, em 2012, a campanha informativa "Compromisso e Atitude pela Lei Maria da Penha - A lei é mais forte" com o intuito de unir e fortalecer os esforços nos âmbito municipal, estadual e federal para dar celeridade aos julgamentos dos casos de violência contra as mulheres e garantir a correta aplicação da Lei Maria da Penha (BRASIL, 2016). Em 2015, foi realizado um estudo pelo Instituto de Pesquisa Econômica Aplicada (BRASIL, 2015) concernente à efetividade da Lei Maria da Penha, através do método denominado "modelo de diferenças em diferenças" no qual se confronta o número de homicídios contra mulheres dentro dos lares com aqueles ocorridos com homens. Os resultados obtidos evidenciam que a Lei Maria da Penha operou uma redução de cerca de 10\% da taxa de homicídio contra as mulheres dentro de suas residências; os autores ressaltam que:

A formulação e sanção da Lei Maria da Penha foi um dos mais empolgantes e interessantes exemplos de 
amadurecimento democrático no Brasil, pois contou com a participação ativa de organizações não governamentais feministas, Secretaria de Política para Mulheres, academia, operadores do direito e o Congresso Nacional. Por outro lado, a lei incorporou aspectos inovadores ao tratar de forma integral o problema da violência doméstica e ao considerar a necessidade de implantação de onze tipos de serviços e medidas protetivas para garantir direitos e tentar levar a paz aos lares. (BRASIL, 2015).

Diante do levantamento realizado acerca dos mecanismos estatais criados com o escopo de se cumprirem as recomendações presentes no Informe de Fundo 54/2001, já analisado anteriormente, a Comissão Interamericana de Direitos Humanos (2016), em relatório anual divulgado em 2016, reconhece os avanços realizados pelo Estado, todavia, sinaliza que ainda permanecem pontos pendentes de cumprimento, concluindo que as recomendações se encontram parcialmente cumpridas.

Outro caso explorado, no presente estudo, refere-se ao primeiro em que o Brasil reconheceu sua responsabilidade internacional pela violação a direitos humanos, firmando um acordo de solução amistosa, mecanismo que permite gerar espaços de diálogo entre peticionários e Estados, nos quais estes podem alcançar acordos que estabelecem medidas de reparação para as presumidas vítimas diretas de violação e para a sociedade em seu conjunto (CIDH, 2003). O caso n. 11.289 a respeito de José Pereira, gravemente ferido, e outro trabalhador, morto, quando ambos tentaram escapar, em 1989, da Fazenda "Espírito Santo", onde haviam sido atraídos com falsas promessas acerca de condições de trabalho, tendo que trabalhar forçadamente, sem liberdade para sair e sob condições inumanas e ilegais, situações vivenciadas junto a mais 60 trabalhadores dessa fazenda. Os fatos denunciados constituíam exemplo da falta de proteção e garantia pelo Estado brasileiro em não responder adequadamente às denúncias relacionadas a essas práticas, comuns nessa região, assim como desinteresse e ineficácia das investigações e processos dos assassinos e responsáveis pela exploração laboral. Em 24 de outubro de 2003, mediante informe n. 95/2003, a Comissão aprovou o acordo de solução amistosa no caso em questão e, como medidas direcionadas ao fortalecimento do marco jurídico no combate à prática de trabalho escravo, o Estado informou, em 2 de janeiro de 2013, as seguintes providências legislativas, a saber, Projeto de Lei n. 5.016/2005, dirigido a reformar o Código Penal no tocante ao estabelecimento de sanções ao trabalho escravo; criação de 500 cargos de delegados e 750 cargos de agentes da Polícia Federal, mediante a Lei n. 11.890/2008; o Projeto de Lei n. 169/2009, orientado a proibir que empresas brasileiras estabeleçam contratos com empresas que explorem trabalho degradante em outros países; o Projeto de Lei n. 603/2011, que se relaciona com as condições de trabalho nas minas de carvão; e o Projeto de Lei n. 1.515/2011, para impedir que os espaços 
públicos de qualquer natureza recebam o nome de pessoas notoriamente envolvidas com a exploração do trabalho escravo (CIDH, 2003). Atualmente, apesar das respectivas propostas legislativas, foi aprovado somente o Projeto de Lei n. 1.515/2011, transformado na Lei Ordinária n. 12.781/2013 ${ }^{4}$ e, apesar de serem instituídos novos cargos na Polícia Federal, referentes a delegados e agentes, persiste grande carência de servidores, como afirmou, em 2015, o então presidente da Associação Nacional dos Delegados de Polícia Federal, Carlos Eduardo Miguel Sobral (COMBATE..., 2015a).

Seguindo à análise dos respectivos informes de mérito, dá-se prosseguimento ao caso n. 11.556, Corumbiara, em que o Estado brasileiro foi responsabilizado internacionalmente por fatos relacionados ao assassinato de trabalhadores integrantes do MST, e pelos ferimentos causados a outras 53 pessoas, por policiais militares, por despejo desses trabalhadores que haviam invadido uma propriedade rural no município de Corumbiara, estado de Rondônia. Em resposta às recomendações feitas pela Comissão, o Estado adotou um conjunto de medidas com propósito de prevenir a violência rural, tais como a criação do programa "Disque Terra e Paz"; do programa "Paz no Campo"; da Comissão Nacional de Combate à Violência no Campo; do Plano Nacional de Combate à Violência no Campo; da criação da Ouvidoria Agrária Nacional (OAN), em 2004, órgão encarregado de prevenir, mediar e reduzir os conflitos agrários. Nesse sentido, diversos foram os casos em que a OAN atuou na prevenção de conflitos, de forma a ilustrar, na Fazenda Córrego Fundo - MG, na Fazenda Jacaré-Curiango - MG, no Acampamento Mário Lago - RJ, na Fazenda Bom Sucesso - MG, na Fazenda Campo Santo - PR (CIDH, 2017). Segundo notícia divulgada, em 19 de fevereiro de 2016, durante a 989 a reunião da Comissão Nacional de Combate à Violência no Campo (CNVC), o desembargador Gercino José da Silva Filho destacou que a atuação da Ouvidoria Agrária Nacional (OAN), no estado de Rondônia, possibilitou a criação de órgãos específicos para mediação de conflitos, como a Delegacia de Polícia Agrária, a Promotoria de Justiça Agrária, Vara Agrária Estadual e Federal, Defensoria Pública Agrária e a designação de policiais militares para agirem em casos de disputas envolvendo trabalhadores rurais e proprietários de terra (BRASIL, 2017). Atualmente, a OAN encontra-se incorporada ao Instituto Nacional de Colonização e Reforma Agrária - INCRA, mediante Decreto n. 8.955/2017, revogado pelo Decreto n. 10.252/2020 (BRASIL, 2020).

O próximo caso a ser exposto refere-se ao tema da discriminação racial, em prejuízo de Simone André Diniz, em que o Estado não garantiu seu pleno direito à justiça

\footnotetext{
$4 \quad$ Situação atual dos projetos de lei mencionados: Projeto de Lei n. 169, de 2009 - aguardando inclusão ordem do dia de requerimento; Projeto de Lei n. 603, de 2011 - arquivado; Projeto de Lei n. 5.016, de 2005 - aguardando parecer do relator na Comissão de Trabalho, de Administração e Serviço Público (CTASP). Disponível em: http://www.camara.leg.br/buscaproposicoesweb/pesquisasimplificada. Acesso em: 30 maio 2017.
} 
e ao devido processo, não conduzindo devidamente os recursos internos para determinar a discriminação racial sofrida pela vítima, segundo informe de fundo n. 66/2006, de 2006 (CIDH, 2006). Dentre as medidas recomendadas pela Comissão, destaca-se aquela referente à realização de modificações legislativas e administrativas necessárias para que a legislação contra o racismo seja efetiva. Em relação a essa recomendação, o Estado brasileiro aprovou, por meio do Decreto n. 8.136/2013, o Estatuto da Igualdade Racial (Lei n. 12.288/2010), com o escopo de se "garantir à população negra a efetivação da igualdade de oportunidades, a defesa dos direitos étnicos individuais, coletivos e difusos e o combate à discriminação e às demais formas de intolerância étnica”. (BRASIL, 2010). Em complemento, o Estado informou sobre a criação da Lei Estadual n. 14.187 de 19 de julho de 2010, que dispõe acerca de penalidades administrativas a serem aplicadas pela prática de atos de discriminação racial, destacando que a criação da Secretaria de Políticas de Promoção da Igualdade Racial da Presidência da República, em 2003, significou um grande avanço na adoção de medidas a fim de se reverter a situação de desigualdade, como as quotas na Educação, no Serviço Público, a implementação da Saúde Integral para a População Negra, e o plano Juventude Viva, dentre outros. Vale reiterar que o Estatuto da Igualdade Racial prevê a instituição de programas de ação afirmativa nos setores público e privado, a constituição do Sistema Nacional de Promoção da Igualdade Racial (SINAPIR), que visa descentralizar as políticas de igualdade racial. A fim de reduzir a violência contra a juventude negra, o Governo Federal lançou, em setembro de 2012, o Plano Viva a Juventude (BRASIL, 2012), consistindo em ações de prevenção para reduzir a vulnerabilidade dos jovens. Sobre a questão do trabalho doméstico, a aprovação da proposta de Emenda Constitucional n. 66 (BRASIL, 2013) que garante 17 novos direitos para os trabalhadores, ampliando garantias ao setor laboral constituído, em sua maioria, por mulheres afrodescendentes, segundo pesquisa realizada pelo Departamento Intersindical de Estatísticas e Estudos Socioeconômicos (DIEESE, 2013). Com o SINAPIR, aprovado pelo Decreto n. 8.136/2013, a política de promoção de igualdade racial deixa de ser uma política de governo e se consolida cada vez mais como uma política de estado em todas as esferas. O caráter transversal dessa política, que é executada por diversos órgãos da administração pública: saúde, educação, trabalho, cultura, assistência social, desenvolvimento agrário, justiça, entre outros, permite e demanda que o órgão de promoção da igualdade racial atue conjuntamente com os demais, no sentido de implementar e acompanhar as políticas públicas que atenderão de forma cidadã essa população (BRASIL, 2013).

Por fim, indicam-se mais dois casos no presente estudo, referentes à temática de atentado contra jornalista, relativos aos informes n. 37/2010, Manoel Leal de Oliveira, e n. 7/2016, Aristeu Guida da Silva e família, nos quais ambos foram assassinados por motivos relacionados ao exercício de sua atividade jornalística, não tendo, o Estado 
brasileiro, adotado medidas para proteger a vida das vítimas e diligência em investigar, julgar e punir os responsáveis pelos respectivos crimes. Nessa perspectiva, em 2012, é criado o Grupo de Trabalho sobre Direitos Humanos dos profissionais de comunicação no Brasil, com o escopo de se analisarem denúncias referentes à situação de violência contra profissionais de comunicação social no exercício dessa função, encaminhá-las aos órgãos competentes e acompanhar seus desdobramentos; propor ações que auxiliem a instituição de um sistema de monitoramento de denúncias referentes às violações aos direitos humanos dessas pessoas; medidas que visem o aperfeiçoamento das políticas públicas voltadas para esse segmento; bem como propor diretrizes para a efetiva segurança dos profissionais de comunicação diante de situações de risco decorrentes do seu exercício profissional. Apesar dos esforços nesse sentido, o Brasil ainda necessita adotar, de forma prioritária, uma política global de proteção dos profissionais da comunicação e centralizar, como política pública, o combate à impunidade em relação ao assassinato, à agressão, à ameaça aos jornalistas, através de investigações exaustivas e independentes de tais fatos, punindo os responsáveis, como recomenda a Comissão (BRASIL, 2016).

\section{Considerações finais}

Diante dos documentos analisados, as violações de direitos humanos foram organizadas em categorias temáticas, a fim de enfatizar e reconhecer pontos sensíveis de proteção, tendo em vista a permanente ocorrência de violações de direitos humanos, a saber: deficitária prestação de justiça, com ausência de garantias judiciais e investigação criminal, violência policial, violência no campo oriunda de conflitos fundiários, violência institucional contra privados de liberdade (sistema carcerário), violência contra defensores de direitos humanos, violência contra menores, violência doméstica, racismo, tortura, escravidão, crimes da ditadura. Nota-se, conforme exposto, que a maioria dos procedimentos envolvendo o Brasil no Sistema Interamericano é engendrada pelo aviltamento a direitos humanos relacionados a deficiências na prestação de justiça e à violência policial em suas diferentes facetas, oriundas de atuações arbitrárias contra trabalhadores rurais, crianças, jovens e defensores de direitos humanos. Nesse sentido, diante da morosidade na condução dos inquéritos policiais, das arbitrariedades acometidas por agentes públicos, a impunidade se consolida como tema frequente nas violações de direitos humanos, referente ao não cumprimento pelo Brasil das garantias da proteção judicial, o que reclama uma reforma processual com o intuito de se eliminar os elementos responsáveis em postergar o resultado definitivo do processo, juntamente a um melhor aparelhamento da polícia, de modo a eliminar interesses particulares arbitrários em sua atuação. 
Ainda, os resultados da análise dos casos envolvendo o Brasil revelam uma notória deficiência do Estado brasileiro referente ao cumprimento de medidas que envolvam modificações no ordenamento jurídico interno; que contenham diferentes agentes estatais e órgãos governamentais relacionados à sua implementação, de modo a se exigir um esforço político de cooperação entre eles; que requeiram a investigação criminal sobre os fatos relacionados, com a devida diligência e em prazo razoável, com o intuito de identificar, processar e punir os responsáveis pelas violações, que promovam a prevenção por meio de formação capacitada de agentes públicos, dentre outras.

Diante do exposto, nota-se que a Comissão Interamericana de Direitos Humanos, no decorrer de seus sessenta anos de existência, vem contribuindo e promovendo implicações na formulação de políticas públicas e legislativas realizadas pelo Estado brasileiro, por meio de ações e programas de governo que respondam às reparações recomendadas pela $\mathrm{CIDH}$ com o escopo de atuar na promoção e defesa dos direitos humanos, contribuindo para o processo de consolidação de um Estado de Direito Democrático. Apesar do muito a ser feito para a consecução de um cenário de efetiva promoção e proteção de direitos humanos, essencial à democracia, há motivos para comemorar as seis décadas de existência da Comissão Interamericana de Direitos Humanos, no que se refere à realidade brasileira.

São Paulo, abril de 2020.

\section{Referências}

ALVES, Alda Judith. O planejamento de pesquisas qualitativas em educação. Cadernos de Pesquisa, São Paulo, v. 77, p. 53-61, maio, 1991.

ALVES, José Augusto Lindgren. Os direitos humanos como tema global. São Paulo: Perspectiva, 1994.

BOBBIO, Norberto. A era dos direitos. Rio de Janeiro: Campus, 2004.

BRASIL. Decreto n. 10.252, de 20 de fevereiro de 2020. Aprova a Estrutura Regimental e o Quadro Demonstrativo dos Cargos em Comissão e das Funções de Confiança do Instituto Nacional de Colonização e Reforma Agrária - Incra, e remaneja cargos em comissão e funções de confiança. Diário Oficial da União, Brasília, DF, Edição 37, Seção 1, p. 2, 21 fev. 2020. Disponível em: http:// www.in.gov.br/web/dou/-/decreto-n-10.252-de-20-de-fevereiro-de-2020-244585036. Acesso em: 24 mar. 2020.

BRASIL. Decreto n. 8.955, de 11 de janeiro de 2017. Aprova a Estrutura Regimental e o Quadro Demonstrativo dos Cargos em Comissão e das Funções de Confiança do Instituto Nacional de Colonização e Reforma Agrária - INCRA, remaneja cargos em comissão e substitui cargos em comissão do Grupo-Direção e Assessoramento Superiores - DAS por Funções Comissionadas do 
Poder Executivo - FCPE (Revogado pelo Decreto n. 10.252, de 2020). Portal do Planalto, Brasília, DF, 12 jan. 2017. Disponível em: http://www.planalto.gov.br/ccivil_03/_ato2015-2018/2017/ decreto/D8955.htm\#art8. Acesso em: 24 mar. 2020.

BRASIL. Lei n. 11.340, de 7 de agosto de 2006. Cria mecanismos para coibir a violência doméstica e familiar contra a mulher, nos termos do $\S 8^{\circ}$ do art. 226 da Constituição Federal, da Convenção sobre a Eliminação de Todas as Formas de Discriminação contra as Mulheres e da Convenção Interamericana para Prevenir, Punir e Erradicar a Violência contra a Mulher; dispõe sobre a criação dos Juizados de Violência Doméstica e Familiar contra a Mulher; altera o Código de Processo Penal, o Código Penal e a Lei de Execução Penal; e dá outras providências. Portal do Planalto, Brasília, DF, ago. 2006. Disponível em: http://www.planalto.gov.br/ccivil_03/_ato2004-2006/2006/ lei/111340.htm. Acesso em: 1 abr. 2020.

BRASIL. Lei n. 12.288, de 20 de julho de 2010. Institui o Estatuto da Igualdade Racial; altera as Leis ${ }^{\text {os }} 7.716$, de 5 de janeiro de 1989, 9.029, de 13 de abril de 1995, 7.347, de 24 de julho de 1985, e 10.778, de 24 de novembro de 2003. Portal do Planalto, Brasília, DF, jul. 2010. Disponível em: http://www.planalto.gov.br/ccivil_03/_ato2007-2010/2010/lei/112288.htm. Acesso em: 24 mar. 2020.

BRASIL. Projeto de Lei n. 4.471, de 2012. Altera os arts. 161, 162, 164, 165, 169 e 292 do DecretoLei n. 3.689, de 3 de outubro de 1941, do Código de Processo Penal. Portal da Câmara dos Deputados, Brasília, DF, set. 2012a. Disponível em: http://www.camara.gov.br/proposicoesWeb/fic hadetramitacao?idProposicao=556267. Acesso em: 30 mar. 2020.

BRASIL. Projeto de Lei n. 6.240, de 2013. Acrescenta art. 149-A ao Decreto-Lei n. 2.848, de 7 de dezembro de 1940 (Código Penal), para tipificar o crime de desaparecimento forçado de pessoa, e acrescenta inciso VIII ao art. $1^{\circ}$ da Lei n. 8.072, de 25 de julho de 1990, para considerar esse crime hediondo. Portal da Câmara dos Deputados, Brasília, DF, 2016. Disponível em: http://www.camara. gov.br/proposicoesWeb/prop_mostrarintegra;jsessionid=9DCB124D86068A1B5D2EF613F1D EDCC7.proposicoesWebExterno1?codteor=1515213\&filename=Parecer-CSPCCO-07-12-2016. Acesso em: 30 mar. 2020. p. 3.

BRASIL. Projeto de Lei n. 6.240, de 2013. Informações de tramitação. Portal da Câmara dos Deputados, Brasília, DF, 2013a. Disponível em: http://www.camara.gov.br/proposicoesWeb/fichad etramitacao?idProposicao=589982. Acesso em: 30 mar. 2020.

BRASIL. Proposta de Emenda à Constituição n. 66, de 2012. Altera a redação do parágrafo único do art. $7^{\circ}$ da Constituição Federal para estabelecer a igualdade de direitos trabalhistas entre os trabalhadores domésticos e demais trabalhadores urbanos e rurais. Portal do Senado, Brasília, DF, abr. 2013b. Disponível em: https://www25.senado.leg.br/web/atividade/materias/-/materia/109761. Acesso em: 3 abr. 2020.

BRASIL. Secretaria Especial de Políticas de Promoção da Igualdade Racial. Política Nacional de Promoção da Igualdade Racial, Brasília, DF, 2003. Disponível em: http://bvsms.saude.gov.br/bvs/ publicacoes/politica_nacional_promocao_igualdade_racial.pdf. Acesso em: 3 abr. 2020. 
BRASIL. Secretaria-Geral da Presidência da República. Plano juventude viva: guia de implementação para Estados e Municípios. Brasília, DF, 2014. Disponível em: https://bibliotecadigital.mdh.gov.br/ jspui/bitstream/192/56/1/SNJ_guia_juventude_viva_2014.pdf. Acesso em: 3 abr. 2020.

BRASIL. Supremo Tribunal Federal. Ação Declaratória de Constitucionalidade 19 Distrito Federal. Relator: Min. Marco Aurélio. Requerente: Presidente da República. Brasília, DF, 9 fev. 2012b. Disponível em: http://redir.stf.jus.br/paginadorpub/paginador.jsp?docTP=TP\&docID=5719497. Acesso em: 24 mar. 2020.

BRASIL. Supremo Tribunal Federal. Ação Direta de Inconstitucionalidade 4.424 Distrito Federal. Relator: Min. Marco Aurélio. Requerente: Procurador-Geral da República. Brasília, DF, 9 fev. 2012c. Disponível em: http://redir.stf.jus.br/paginadorpub/paginador.jsp?docTP=TP\&docID=6393143. Acesso em: 24 mar. 2020.

BUERGENTHAL, Thomas. The Inter-American System for the protection of human rights. In: MERON, Theodor (ed.). Human rights in international law: legal and policy issues. Oxford: Clarendon Press, 1984.

CANOTILHO, José Joaquim Gomes. Direito constitucional e teoria da constituição. Coimbra: Almedina, 2004.

CERQUEIRA, Daniel; MATOS, Mariana Vieira Martins; MARTINS, Ana Paula Antunes; PINTO JUNIOR, Jony. Textos para discussão: avaliando a efetividade da Lei Maria da Penha. Brasília, DF: IPEA, mar. 2015. Disponível em: http://www.ipea.gov.br/portal/images/stories/PDFs/TDs/td_2048. pdf. p. 14-34. Acesso em: 1 abr. 2020.

CIDH - COMISSÃO INTERAMERICANA DE DIREITOS HUMANOS. Disponível em: http:// www.oas.org/pt/cidh/. Acesso em: 8 jan. 2020.

CNJ. Conselho Nacional de Justiça. XIII Jornada: Lei Maria da Penha. Brasília, DF, 9 ago. 2019. Disponível em: https://www.cnj.jus.br/programas-e-acoes/violencia-contra-a-mulher/. Acesso em: 24 mar. 2020.

COMBATE à corrupção ganha reforço de cerca de 600 novos policiais federais. Associação Nacional dos Delegados de Polícia Federal, Brasília, DF, 28 dez. 2015. Disponível em: http://adpf. org.br/adpf/admin/painelcontrole/materia/materia_portal.wsp?tmp.edt.materia_codigo=7823\&wi. redirect=ECRL1V3GXPGOOLSORTQV\#.WYz0CFGGPIV, p. 83. Acesso em: 28 mar. 2020.

COMPROMISSO e atitude: a Lei Maria da Penha. O que é a campanha Compromisso e Atitude pela Lei Maria da Penha. [S. l.: s. n.], 10 mar. 2016. Disponível em: http://www.compromissoeatitude. org.br/o-que-e-a-campanha-compromisso-e-atitude-pela-lei-maria-da-penha. Acesso em: 26 mar. 2020 .

CONDEGE. Colégio Nacional dos Defensores Públicos Gerais. Comissões especializadas. Brasília, DF. Disponível em: http://www.condege.org.br/comissoes.html. Acesso em: 24 abr. 2020. 
DIEESE. O emprego doméstico no Brasil. Estudos e Pesquisas, São Paulo, n. 68, 27 p., ago. 2013. Disponível em: https:/www.dieese.org.br/estudosetorial/2013/estPesq68empregoDomestico.pdf. Acesso em: 3 Abr. 2020.

GUERRA, Sidney. Direitos humanos na ordem jurídica internacional e reflexos na ordem constitucional brasileira. Rio de Janeiro: Lumen Juris, 2008.

LEWANDOWSKI, Enrique Ricardo. Proteção dos direitos humanos na ordem interna e internacional. Rio de Janeiro: Forense, 1984.

NOVA estrutura do Incra incorpora Ouvidoria Agrária e cria Corregedoria-Geral. Portal SóNotícias, [s. l.], 13 jan. de 2017. Disponível em: https://www.sonoticias.com.br/agronoticias/nova-estruturado-incra-incorpora-ouvidoria-agraria-e-cria-corregedoria-geral/. Acesso em: 1 jun. 2017.

OAS. Estatísticas sobre as atividades da Comissão Interamericana de Direitos Humanos. Disponível em: http://www.oas.org/es/cidh/multimedia/estadisticas/estadisticas.html. Acesso em: 20 mar. 2020.

OEA. Comisión Interamericana de Derechos Humanos. Informe Anual 2016. Disponível em: http:// www.oas.org/es/cidh/docs/anual/2016/docs/InformeAnual2016cap2Dseguimiento-es.pdf. p. 79. Acesso em: 23 mar. 2020. Ver: http://www.oas.org/es/cidh/docs/anual/2016/indice.asp.

OEA. Comisión Interamericana de Derechos Humanos. Informe Anual 2016. Disponível em: http:// www.oas.org/es/cidh/docs/anual/2016/docs/InformeAnual2016cap2Dseguimiento-es.pdf. p. 96. Acesso em: 8 jun. 2017. Ver: http://www.oas.org/es/cidh/docs/anual/2016/indice.asp.

OEA. Comisión Interamericana de Derechos Humanos. Informe n. 7/16. Caso 12.213. [S. l.], 13 abr. 2016. Disponível em: http:/www.oas.org/es/cidh/decisiones/2016/brpu12213es.pdf. Acesso em: 20 mar. 2020.

OEA. Comisión Interamericana de Derechos Humanos. Informe n. 54/01. Caso 12.051. Brasília, DF, 16 abr. 2001. Disponível em: http://www.cidh.oas.org/annualrep/2000sp/CapituloIII/Fondo/ Brasil12.051.htm. Acesso em: 22 mar. 2020.

OEA. Comisión Interamericana de Derechos Humanos. Informe n. 95/03. Petición 11.289. Brasília, DF, 24 oct. 2003. Disponível em: http://www.cidh.oas.org/annualrep/2003sp/Brasil.12289.htm. Acesso em: 28 maio 2017.

OEA. Comissão Interamericana de Direitos Humanos. Convenção Americana sobre Direitos Humanos. San José, 22 nov. 1969. Disponível em: https://www.cidh.oas.org/basicos/portugues/c. convencao_americana.htm. Acesso em: 8 jan. 2020.

OEA. Comissão Interamericana de Direitos Humanos. Regulamento da Comissão Interamericana de Direitos Humanos. [S. l.], out./nov. 2009. Disponível em: http://www.cidh.oas.org/basicos/ portugues/u.regulamento.cidh.htm. Acesso em: 28 jan. 2017. 
OEA. Comissão Interamericana de Direitos Humanos. Relatório n. 32/04. Caso 11.556. [S. l.], 11 mar. 2004. Disponível em: https://cidh.oas.org/pdf\%20files/Brasil\%2011.556\%20Corumbiara\%20 PUBL\%20Port.pdf. Acesso em: 20 mar. 2020.

OEA. Comissão Interamericana de Direitos Humanos. Relatório n. 34/00. Caso 11.291. Brasília, DF, 13 abr. 2000. Disponível em: http://www.cidh.oas.org/annualrep/99port/Brasil11291.htm. Acesso em: 20 mar. 2020.

OEA. Comissão Interamericana de Direitos Humanos. Relatório n. 37/10. Caso 12.308. [S. l.], 17 mar. 2010. Disponível em: https://cidh.oas.org/annualrep/2010port/BRPU12308PORT.DOC. Acesso em: 20 mar. 2020.

OEA. Comissão Interamericana de Direitos Humanos. Relatório n. 66/06. Caso 12.001. [S. l.], 21 out. 2006. Disponível em: http://www.cidh.org/annualrep/2006port/brasil.12001port.htm. Acesso em: 20 mar. 2020.

OEA. Corte Interamericana de Direitos Humanos. Disponível em: http://www.oas.org/pt/cidh/. Acesso em: 8 jan. 2020.

OLIVEIRA, Maria Marly de. Como fazer pesquisa qualitativa. Petrópolis: Vozes, 2007.

RAMOS, André de Carvalho. Curso de direitos humanos. São Paulo: Saraiva, 2014.

RAMOS, André de Carvalho. Processo internacional de direitos humanos: análise dos mecanismos de apuração de violações. 2. ed. São Paulo: Saraiva, 2012.

RANIERI, Nina Beatriz Stocco. Teoria do estado: do estado de direito ao estado democrático de direito. Barueri, SP: Manole, 2013.

RIBEIRO, Maria de Fátima; MAZZUOLI, Valerio de Oliveira (coord.). Direito internacional dos direitos humanos: estudos em homenagem à professora Flávia Piovesan. Curitiba: Juruá, 2004.

SILVA, José Afonso da. Curso de direito constitucional positivo. São Paulo: Malheiros Editores, 1992.

TRINDADE, Antônio Augusto Cançado. O sistema interamericano de direitos humanos no limiar do novo século: recomendações para o fortalecimento de seu mecanismo de proteção. In: GOMES, Luiz Flávio; PIOVESAN, Flávia. O sistema interamericano de proteção dos direitos humanos e o direito brasileiro. São Paulo: Revista dos Tribunais, 2000. 
